\title{
CLINICO-EPIDEMIOLOGICAL PROFILE OF ACUTE WATERY DIARRHOEA IN UNDER FIVE CHILDREN WITH SPECIAL REFERENCE TO ROTAVIRUS INFECTION
}

\author{
Prakhar Nyati', Prachi Choudhary², Sharad Thora ${ }^{3}$ \\ 13rd Year Resident, Department of Paediatrics, MGM Medical College, Indore, Madhya Pradesh, India. \\ ${ }^{2}$ Associate Professor, Department of Paediatrics, MGM Medical College, Indore, Madhya Pradesh, India. \\ 3 Professor, Department of Paediatrics, MGM Medical College, Indore, Madhya Pradesh, India.
}

\begin{abstract}
\section{BACKGROUND}

Diarrhoeal disorders in childhood accounts for a large proportion (9\%) of childhood deaths with an estimated 0.71 million dea ths per year globally, making it the second most common cause of child deaths worldwide. In early childhood, the single most important cause of severe dehydrating diarrhoea is rotavirus infection. We wanted to identify cases of rotavirus among children less than five years of age hospitalized for acute watery diarrhoea and to determine the circulating rotavirus genotypes and to identify any seasonal variation in rotavirus infectivity.
\end{abstract}

\section{METHODS}

A prospective observational study was conducted in MY hospital Indore over a period of 15 months, during which, 295 children aged less than 5 years who were admitted with acute watery diarrhoea were enrolled, their stool samples collected, and analysed, for rotavirus genotype.

\section{RESULTS}

Rotavirus positive diarrhoea cases were 74 out of total 295 children enrolled, of which 44 positive cases were aged less than 1 year. 40 positive cases were reported in the winter months of October to January.

\section{CONCLUSIONS}

Prevalence of rota viral diarrhoea in our study is $25 \%$. Most common age group affected by rotavirus is less than one year. Rotavirus infection is more common in the winter season. Most common genotype of rotavirus causing diarrhoea in our setting is G3P8.

HOW TO CITE THIS ARTICLE: Nyati P, Choudhary P, Thora S. Clinico-epidemiological profile of acute watery diarrhoea in under five children with special reference to rotavirus infection. J. Evolution Med. Dent. Sci. 2019;8(14):1141-1144, DOI: $10.14260 /$ jemds/2019/253

\section{BACKGROUND}

Diarrhoeal disorders in childhood account for a large proportion $(9 \%)$ of childhood deaths, with an estimated 0.71 million deaths per year globally, making it the second most common cause of child deaths worldwide. Global Mortality may be declining rapidly, but the overall incidence of diarrhoea has only declined from 3.4 to approximately 2.9 episodes per child-year in the past 2 decades. Rotavirus, Norovirus and E.coli are responsible for more than half of all diarrheal deaths in under five-year-old children.(1)

Rotaviruses were observed to be responsible for the majority of cases of acute gastroenteritis requiring hospital admission in children below the age of 5 all around the world, and to be associated with high mortality rates in developing countries (2) Worldwide, rotavirus is estimated to cause more than 111 million cases of diarrhoea annually in children younger than 5 years of age. Of these, 18 million cases are considered at least moderately severe, with approximately 500,000 deaths per year. (3)

'Financial or Other Competing Interest': None.

Submission 01-02-2019, Peer Review 27-03-2019,

Acceptance 01-04-2019, Published 08-04-2019.

Corresponding Author:

Dr. Prakhar Nyati,

\#15A, Maa Durga Nagar,

Near Agrawal Nagar,

Indore, Madhya Pradesh, India.

E-mail: prakharnyati1991@gmail.com

DOI: $10.14260 /$ jemds $/ 2019 / 253$

\section{(c) (i) $\$$}

The first licensed vaccine (RotaShield), a live oral tetravalent vaccine, was withdrawn following an association with intussusceptions. Two live-attenuated oral vaccines are currently used worldwide. Rotarix is a monovalent vaccine of rotavirus strain G1P8 attenuated in Vero cell culture. RotaTeq is a pentavalent vaccine of the five strains (G1-G4 and P8) reassorted between bovine and human WC3 rotaviruses and attenuated by Vero cell culture. ROTAVAC is an indigenous monovalent human-bovine recombinant live-attenuated vaccine based on G9P11 or 116E strain, manufactured in India. Rotavirus vaccination is introduced in UIP in 2016 in selected districts in four states (Andhra Pradesh, Himachal Pradesh, Haryana and Odisha) using the ROTAVAC Vaccine.(4)

\section{Primary Objectives}

To identify cases of rotavirus among children less than five years of age hospitalized for acute watery diarrhoea and to determine the circulating rotavirus genotypes.

\section{Secondary Objectives}

1. To correlate the nutritional status of children with the severity of disease.

2. To identify seasonal variation in rotavirus infectivity.

\section{METHODS}

The study design was prospective observational type and was conducted in the Department of Paediatrics, M.G.M. Medical College and Associated Maharaja Yashwant Rao Hospital, Indore and Chacha Nehru Bal Chikitsalaya (CNBC), Indore from June 2017 to August 2018. Following approval from 
Institutional Ethics committee in June 2017 all children aged less than 5 years, admitted in MY Hospital and CNBC Hospital Indore with acute watery diarrhea were selected.

\section{Method of Data Collection}

We visited the hospital wards daily for enrolling cases admitted with acute diarrhoea. All children satisfying the inclusion criteria (Less than 5 years of age presenting with acute diarrhoea and admitted as In-patients or treated in the Emergency Department for at least 6 hours) were enrolled after obtaining informed and written consent from the parent. Chronic diarrhoea (Diarrhoea more than 7 days) and dysentery were excluded from the study. Detailed clinical history including epidemiological factors was taken, clinical examination was done, and management was started according to standard protocols. Routine investigations (CBC, RFT) were sent. Patients were classified according to weight for age as per Indian Academy of Pediatrics classification into- No PEM- $>81 \%$ of normal age for sex; Grade I PEM- 7180\%; Grade II PEM- 61-70\%; Grade III PEM- 51-60\%; Grade IV PEM- $<50 \%$. Vaccination history was collected from all enrolled case-patients. The parent or guardian was asked for each child's vaccination card. Sufficient amount of whole stool (5 - $10 \mathrm{~g}$ or $\mathrm{ml}$ ) was collected in a sterile screw capped container by the patient attendant/ hospital staff within 48 hrs of admission. At CNBC stool samples were kept at $-20^{\circ} \mathrm{C}$ laboratory (freezer cabinet of refrigerator) until shipment to CMC Vellore and transported in a vaccine carrier/ thermocol box with frozen gel packs. At CMC Vellore, stool samples were tested by Enzyme Immunoassay and serotyping of rotavirus was done in rotavirus positive samples. A confirmed case of acute rotavirus AGE was defined as any case of acute diarrhea in which rotavirus is demonstrated by enzyme immunoassay (EIA) testing of stool.

\section{Statistical Tests Applied}

Chi square test- for association between two variables Software used- SPSS Statistics Solution (Statistical Analysis Software) SPSS version 20.0

\section{RESULTS}

Out of the total 295 patients enrolled in our study, 74 patients came out to be positive for rotavirus antigen in stools implying $25.08 \%$ prevalence of rota viral diarrhoea in our study. Age group in which Rotavirus diarrhoea was found to be most prevalent in our study is below 12 months (59.5\%) followed by 12-24 months age group (33\%). In our study it was found that $54.7 \%$ of patients (163 patients) had background of Protein-Energy Malnutrition according to IAP Classification; Rotavirus Positivity (54\%) was found to be more common in patients not having PEM background (40 patients). Almost 54 percentage of Rotavirus Positive cases were found in the cooler months of October, November, December and January.

Rotavirus Vaccine coverage in Malwa region (Indore) is very less. Only 10 patients $(3.4 \%)$ had received rotavirus vaccine. All these patients were negative for rotavirus antigen in stools. Overall most prevalent strain of rotavirus causing diarrhoea in hospitalized patients in Indore is G3 (P8).

Mean duration of stay in Rotavirus Positive patients was less (2.42 days) when compared to Rotavirus Negative patients (3.12 days) ( $\mathrm{p}$ value 0.022 ). No patients certified in the rotavirus positive group and 3 patients (1\% of total AGE patients admitted) certified in the rotavirus negative group.

\begin{tabular}{|c|c|c|c|}
\hline Age Group & $\begin{array}{l}\text { Rotavirus } \\
\text { Negative }\end{array}$ & $\begin{array}{l}\text { Rotavirus } \\
\text { Positive }\end{array}$ & Total \\
\hline$<12$ Months & $131(59.3 \%)$ & 44 (59.5\%) & $175(59.3 \%)$ \\
\hline 12-24 Months & $48(21.7 \%)$ & $25(33.8 \%)$ & $73(33 \%)$ \\
\hline 24-36 Months & $17(7.7 \%)$ & $4(5.4 \%)$ & $21(7.1 \%)$ \\
\hline 36-48 Months & $17(7.7 \%)$ & $1(1.3 \%)$ & $18(6.5 \%)$ \\
\hline 48-60 Months & $8(3.6 \%)$ & 0 & $8(2.7 \%)$ \\
\hline Total & 221 & 74 & 295 \\
\hline \multicolumn{4}{|c|}{$\begin{array}{c}\text { Table 1. Incidence of Rotaviral Diarrhoea in Different Age } \\
\text { Groups }\end{array}$} \\
\hline \multicolumn{4}{|c|}{$\begin{array}{c}\text { Pearson Chi-Square test applied; P-Value }=<0.001 \\
\text { (significant) }\end{array}$} \\
\hline
\end{tabular}

\begin{tabular}{|c|c|c|c|c|c|}
\hline $\begin{array}{c}\text { Genotype } \\
\text { (VP7) }\end{array}$ & $\begin{array}{c}\text { Number } \\
\text { of } \\
\text { Patients } \\
\text { Positive }\end{array}$ & $\%$ & $\begin{array}{c}\text { Geno- } \\
\text { type } \\
\text { (VP4) }\end{array}$ & $\begin{array}{c}\text { Number } \\
\text { of } \\
\text { Patients } \\
\text { Positive }\end{array}$ & $\%$ \\
\hline G3 & 39 & $52.7 \%$ & P8 & 45 & $60.8 \%$ \\
\hline G9 & 5 & $6.8 \%$ & P6 & 8 & $10.8 \%$ \\
\hline G2 & 4 & $5.4 \%$ & P4 & 7 & $9.5 \%$ \\
\hline G12 & 1 & $1.4 \%$ & P4+P8 & 1 & $1.4 \%$ \\
\hline G1+G9 & 1 & $1.4 \%$ & P6+P8 & 1 & $1.4 \%$ \\
\hline G1+G3 & 1 & $1.4 \%$ & UT & 8 & $10.8 \%$ \\
\hline G3+G9+G10 & 1 & $1.4 \%$ & & & \\
\hline UT & 12 & $16.2 \%$ & & & \\
(untypable) & \multicolumn{7}{|c|}{ Table 2. Serotype of Rotavirus } \\
\hline \multicolumn{7}{|c|}{$<0$ not significant) } \\
\hline Pearson Chi square test applied; Value- 0.3258 (p value \\
\hline
\end{tabular}

\begin{tabular}{|c|c|c|c|}
\hline Outcome & Discharged & Certified & All \\
\hline Rotavirus Negative & $219(98.6 \%)$ & $3(1.4 \%)$ & 221 \\
\hline Rotavirus Positive & $74(100 \%)$ & 0 & 74 \\
\hline All & $292(99 \%)$ & $3(1 \%)$ & 295 \\
\hline \multicolumn{4}{|c|}{ Table 3. Outcome of Cases } \\
\hline Pearson Chi-Square test applied; p Value $=0.329$ \\
(not significant)
\end{tabular}

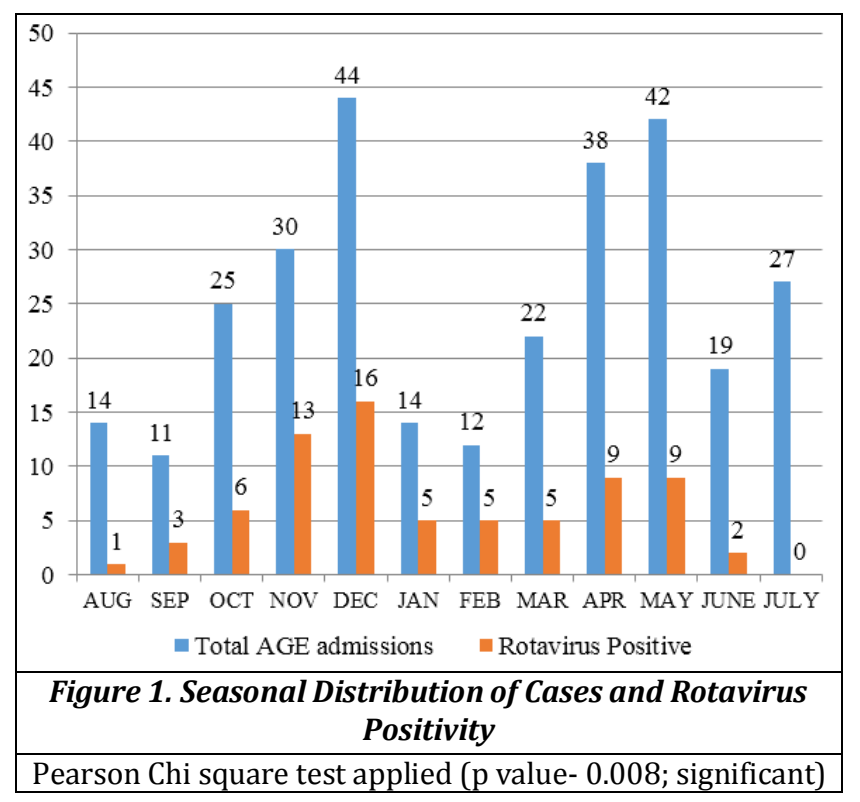




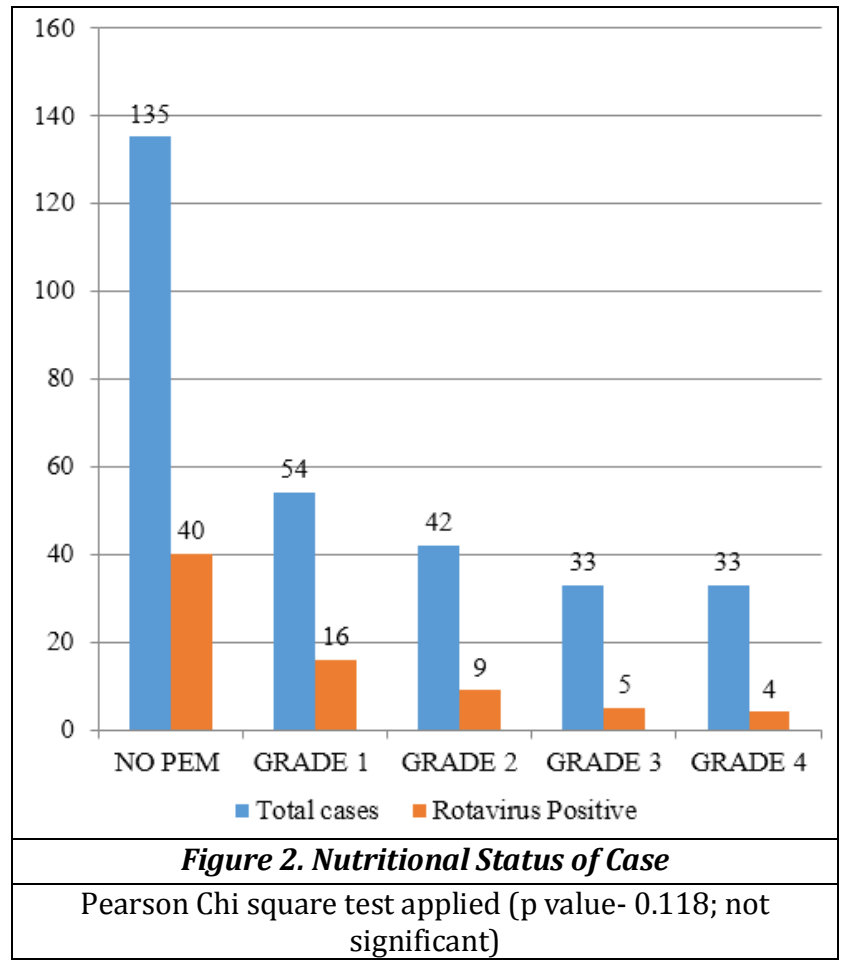

\section{DISCUSSION}

\section{Prevalence of Rotavirus}

Global prevalence of Rotavirus gastroenteritis in children below 5 years varies from $6 \%$ to $56 \%$ whereas in India the incidence of Rotavirus diarrhoea is from $5 \%$ to $89.9 \%$ [5]. In our study the Prevalence of Rotavirus diarrhoea in children aged less than 5 years is $25 \%$ which is in accordance with a study conducted by Dr. R. Senthilkumar in Coimbatore, in which prevalence of Rotavirus infection was $24 \%$.(6) Desai et al., from a hospital based study reported $23.5 \%$ of prevalence in children less than five years.

\section{Rotavirus Infectivity in Different Age Group and Sex}

Age group in which Rotavirus diarrhoea was found to be most prevalent in our study is below 12 months (59.5\%) followed by $12-24$ months age group (33\%). Our findings are in concordance with various studies conducted previously. In a study conducted by R. Senthilkumar in Coimbatore, the peak incidence of Rotavirus occurred in the age group of 6 to 12 months (58.3\%).(7) It also correlates with a study by Bahl R et al., in which the result showed the peak incidence of Rotavirus in the age group of 9 to 11 months and a decrease considerably after 18 months of age [8]. The higher frequency of Rotavirus diarrhoea in this age group of 6 to 12 months $(59.5 \%)$ is because of weaning from breast feed and introduction of artificial feeds. The chance of infection tends to increase when breast feed is withdrawn since the protective antibodies are lost. Furthermore, introduction of artificial feed is linked with increased risk of infection unless proper hygienic measures are strictly followed.

The occurrence of Rotavirus declined sharply after 2 years of age $(6.7 \%)$. This is because of subsequent infections that usually occur less severely due to the antibodies formed against previous exposure to Rotavirus. [9]

\section{Rotavirus Vaccine Coverage}

Rotavirus Vaccine coverage in Malwa region (Indore) is very less. Only 10 patients $(3.4 \%)$ had received rotavirus vaccine.
All these patients were negative for rotavirus antigen in stools. The present number is too small to conclude for vaccine effectiveness. Now that rotavirus vaccine is available in government sector, this coverage is expected to improve. Interventions such as improved hygiene, sanitary measures and drinking water do not adequately prevent the diarrhoea caused by rotavirus. Besides that, there is delay in accessing health care facilities thereby affecting timely intervention and prognosis. Therefore, vaccination is the best way of protecting children from Rotavirus infection and thus reducing disease burden and mortality. India has developed a new vaccine against Rotavirus - ROTAVAC in May 2013. Indian Academy of Paediatrics has recommended inclusion of Rotavirus vaccine in the National Immunization Program [10]. It is found that the ROTAVAC reduced severe diarrhoea by more than $56 \%$ during first year of life with protection continuing into the second year also.

\section{Seasonal Variation in Rotavirus Infectivity}

Almost 54 percentage of Rotavirus Positive cases were found in the cooler months of October, November, December and January. In this present study, Rotavirus peak occurred during the cooler months (October to January) of the year than other months. This study correlated with the study done by Bahl R et al., which also showed, there was a distinct peak of rotavirus diarrhoea in winter months (November to February).[11] Another study by Rahoni SM et al., observed a seasonal pattern of Rotavirus diarrhoea in association with cooler months [12]. It is postulated that the reason behind seasonal pattern of Rotavirus infection is because of the possibility of survival of the virus in the environment and its transmission enhanced by low humidity as well as low temperature,[13] higher rainfall also enhances the incidence of Rotavirus infection. It was also noted that, there was no such typical seasonal pattern of Rotavirus in tropical countries due to high temperature and humidity as well as high birth rates.[14]

\section{Prevalent Genotypes of Rotavirus}

Most common strain of rotavirus causing diarrhoea in our study is G3 (P8) which is in contrast with a study conducted by Sanjay Mehendale in Chennai in 2015 in which most common genotype found was G1P8 (62.7\%).(15) A study conducted by Preeti Jain in Pune in 2014 also showed G1P8 (73.8\%) as the most common genotype.(16)

A study conducted by Bahl R in New Delhi in 2005 showed G1 to be the most commonly isolated serotype in Indian studies followed by G2 and G untypeable. On regional distribution, in northern India, G1 was the most common serotype isolated. In Western India, G2 was predominant. In Eastern India, G1 was detected most commonly. In southern India, G1 was Predominant. $(17,18)$

A study conducted by Mishra V in New Delhi in 2010 showed P6 to be most common in Northern India. In western and eastern India, Prevalence of P4 was higher than other serotypes. In southern India, Untypeable P type was most commonly documented closely followed by P8. $(17,18)$

\section{Morbidity and Mortality Associated with Rotavirus Infection}

Mean duration of stay in Rotavirus Positive patients was less (2.42 days) when compared to Rotavirus Negative patients (3.12 days) ( $p$ value 0.022 ). 
No patients certified in the rotavirus positive group and 3 patients ( $1 \%$ of total AGE patients admitted) certified in the rotavirus negative group.

These findings are not in concordance with other previous studies. In other studies, it was found that rotavirus positive children had more dehydration and longer duration of diarrhoea and thus longer hospital stay and mortality.

A study conducted by Neeraj Teotia in Meerut in 2014 found duration of stay to be 76.1 hours (3.17 days) in rotavirus positive patients as compared to 76.5 hours (3.19 days) in rotavirus negative groups.(19)

The reported low mortality (1\%) among hospitalized children with acute gastroenteritis could not be attributed to rotavirus infection. This probably reflects that an effective diarrheal disease management protocol is practised in the health care facility participated in this study. It would be necessary to study the community burden of rotavirus gastroenteritis and related morbidity and mortality outcomes to know the true burden in the community settings and nonhospitalized children.

\section{Recommendation}

Prevalence of Rotavirus in Indore as found in our study is $25 \%$; vaccine coverage of rotavirus is very poor (only $3.4 \%$ ); it is thus recommended to improve the rotavirus vaccine coverage. Rotavirus vaccine (ROTAVAC) was launched in Madhya Pradesh under Universal Immunization Program in April, 2017. So, rotavirus vaccine coverage is expected to significantly improve in further years. As rotavirus vaccines are introduced into the UIP in India, monitoring their public health impact is a high priority. Marked reduction in child deaths and hospitalizations from rotavirus AGE are anticipated, and documenting these benefits will be vital to ensure sustained support for widespread use of vaccine among policy makers and health care providers in India. If vaccine effectiveness is found to be unsatisfactory, the findings must be scrutinized to determine the need to modify vaccination schedules or formulations to further enhance vaccine performance. So by continuing this study on a larger scale we would like to assess the effect of rotavirus vaccine on morbidity and mortality in acute watery diarrhoea patients aged less than 5 years old.

\section{CONCLUSIONS}

Prevalence of rota viral diarrhoea in our study is $25 \%$. Most common age group affected by rotavirus is less than one year. Rotavirus infection is more common in the winter season. Most common genotype of rotavirus causing diarrhoea in our setting is G3P8.

\section{REFERENCES}

[1] Bhutta ZA. Acute gastroenteritis in children; the digestive system. In: Kliegman RM, Marcdante K, Misra OP, eds. Nelson textbook of pediatrics. First South Asia Edition, Vol. 2, Elsevier 2016: p. 1854.

[2] Meurman $\mathrm{OH}$, Laine MJ. Rotavirus epidemic in adults. N Engl J Med 1977;296(22):1298-9.

[3] Bass DM. Rotaviruses, calciviruses and astroviruses; infectious diseases. In: Kliegman RM, Marcdante K, Misra OP, eds. Nelson textbook of pediatrics. First South Asia Edition, Vol. 2, Elsevier 2016: p. 1616.
[4] Sinha A, Singh S. Immunization and immunodeficiency. In: Paul VK, Bagga A, eds. Ghai essential paediatrics. 9th edn. 2018: p. 194.

[5] Alam MM, Pun SB, Gauchan P, et al. The first identification of rotavirus $\mathrm{B}$ from children and adults with acute diarrhoea in Kathmandu, Nepal. Trop Med Health 2013;41(3):129-34.

[6] Sumi A, Rajendran K, Ramamurthy T, et al. Effect of temperature, relative humidity and rainfall on rotavirus infection in Kolkata, India. Epidemol infec 2013;141(8):1652-61.

[7] Senthilkumar R, Mythily N. A study on rotavirus gastroenteritis in children under five years in Coimbatore. Master's thesis, Coimbatore Medical College, Coimbatore. http://repositorytnmgrmu.ac.in/4738/1/200400717s enthilkumar.pdf

[8] Gupta N, Jain SK, Ratnesh, et al. An evaluation of diarrheal diseases and acute respiratory infections control programs in a Delhi slum. Indian J Pediatr 2007;74(5):471-6.

[9] Vesikari T, Matson D0, Dennehy P, et al. Safety and efficacy of pentavalent human-bovine (WC3) reasons for Rotavirus vaccine. N Engl J Med 2006:354(1):2333.

[10] Bhandari N, Rongsen-Chandola T, Bavdekar A, et al. Efficacy of a monovalent human-bovine (116E) rotavirus vaccine in Indian infants: a randomised, double-blind, placebo-controlled trial. Lancet 2014;383(9935):2136-43.

[11] Park K. Epidermiology of communicable diseases. In: Textbook of preventive end social medicine. 19th edn. Jabalpur. India: Banarsidas Bhanot 2007:142-7.

[12] Shariff M, Deb M, Singh R. A study of diarrhoea among children in Eastern Nepal with reference to rotavirus. Indian J Med Microbiol 2003;21(2):87-90.

[13] Modi B. Rotavirus diarrhoea - current scenario and preventive strategies. National Journal of Medical Research 2013;3(2):104-5.

[14] Zarani AH, Modarres SH, Jadali F, et al. Role of rotaviruses in children with acute diarrhoea in Tehran, Iran. J Clin Virol 2004;29(3):189-93.

[15] Mehendale S, Venkatasubramanian S, Girish Kumar CP, et al. Expanded Indian national rotavirus surveillance network in the context of rotavirus vaccine introduction. Indian Pediatr 2016;53(7):575-81.

[16] Jain P, Varanasi G, Ghuge R, et al. Rotavirus Infections in Children Vaccinated Against Rotavirus in Pune, Western India. Indian Pediatr 2016;53(7):589-93.

[17] Bahl R, Ray P, Subodh S, et al. Incidence of severe rotavirus diarrhea in New Delhi, India, and G and P types of the infecting rotavirus strains. J Infect Dis 2005;192 Suppl 1;S114-9.

[18] Kumar A, Basu S, Vashishtha V, et al. Burden on rotavirus diarrhoea in under-five Indian children. Indian Pediatr 2016;53(7):607-17.

[19] Teotia N, Upadhyay A, Agarwal S, et al. Rotavirus diarrhea in children presenting to an urban hospital in western Uttar Pradesh, India. Indian Pediatr 2016;53(7):627-9. 